A reflexive exploration of transposing comparative paradigms into scholarly and practical approaches in teacher education

Florin D. Salajan 


\title{
A reflexive exploration of transposing comparative paradigms into scholarly and practical approaches in teacher education
}

\author{
Florin D. Salajan ${ }^{a^{*}}$ \\ ${ }^{a}$ North Dakota State University, 1400 Centennial Blvd FLC 210A, Fargo ND 58108, USA \\ *Corresponding author: florin.salajan@ndsu.edu
}

\section{Abstract}

\section{Keywords:}

comparative and international education; teacher education; scholarship; curriculum; practice.
This article examines the place of comparative and international education (CIE) scholarship and practice in teacher education (T.Ed.). In this regard, CIE scholarship is instrumental in revealing the functioning, organization, importance and interconnectedness of teaching, as a profession, and teacher education, as the conduit to that profession, across national and cultural settings. As teacher education programs and teacher educators continue their work in imparting robust and sound pedagogical knowledge, they also need to acknowledge the enriching nature of a comparative perspective in the scholarship and practice on teacher education. Thus, including comparative methods in examining teacher education both within and across a program's national borders offers teachers-to-be a window into an array of teaching practices in a global setting. Developing an awareness, interest and inclination toward a comparative perspective-taking in teacher education is paramount in forming the new generations of teachers and researchers on teacher education. At the same time, teacher education programs benefit from research collaborations across national and cultural settings, allowing them the possibility to co-learn what approaches may work in meaningfully adjusting their curricular organization to prepare teachers for an interconnected world in which their students truly become global citizens.

\section{Zusammenfasung}

Schlüsselworte:

vergleichende und internationale Bildung; Lehrer Ausbildung; Stipendium; Curriculum; Praxis.
Dieser Artikel untersucht den Stellenwert von Stipendien und Praxis der vergleichenden und internationalen Bildung (VIB) in der Lehrerausbildung (L.Ab.). In dieser Hinsicht trägt das VIB-Stipendium maßgeblich dazu bei, die Funktionsweise, Organisation, Bedeutung und Vernetzung des Lehrberufs und der Lehrerausbildung als Weg zu diesem Beruf über nationale und kulturelle Kontexte hinweg aufzuzeigen. Während Lehrerbildungsprogramme und Lehrerausbilder ihre Arbeit zur Vermittlung solider und widerstandsfähiger pädagogischer Kenntnisse fortsetzen, müssen sie auch den bereichernden Charakter einer vergleichenden Perspektive in der Wissenschaft und Praxis der Lehrerbildung anerkennen. Daher bietet die Einbeziehung vergleichender Methoden bei der Untersuchung der Lehrerbildung sowohl innerhalb als auch über die nationalen Grenzen eines Programms hinweg angehenden Lehrern einen Einblick in eine Reihe von Unterrichtspraktiken in einem globalen Umfeld. Die Entwicklung eines Bewusstseins, Interesses und einer Neigung zu einer vergleichenden Perspektivenübernahme in der Lehrerbildung ist von größter Bedeutung für die Bildung der neuen Generationen von Lehrern und Forschern in der Lehrerbildung. Gleichzeitig profitieren Lehrerbildungsprogramme von Forschungskooperationen über nationale und kulturelle Kontexte hinweg, was ihnen die Möglichkeit gibt, gemeinsam zu lernen, welche Ansätze bei der sinnvollen Anpassung ihrer Lehrplanorganisation funktionieren können, um Lehrer auf eine vernetzte Welt vorzubereiten, in der ihre Schüler wirklich globale Bürger werden.

\section{A brief overview of comparative education paradigms}

Although not immediately evident, Comparative and International Education (CIE) and Teacher Education (T.Ed.) have nonetheless long been associated fields and they have intersected throughout their historical development as fields of scholarly inquiry and practice. From early on, comparativists were not only concerned with an overall analysis of educational systems between countries, but were also interested to a large extent in the very teaching practices occurring in those systems. For instance, early $19^{\text {th }}$ century scholar Marc Antoine Jullien de Paris, considered as one of the founders of the field of comparative education (Epstein, 2017) advocated for the establishment of a Normal Institute of Education for Europe to provide training for teachers in the most advanced teaching techniques available at the time on the continent (Hayhoe, Manion, \& Mundy, 2017). He thought that the publication of regular reports 
containing comparative data on teaching across countries in Europe would inform not only the managers of educational apparatuses, but more importantly the teachers themselves to learn about practices in other countries and to avoid being easily manipulated by those who controlled the educational systems in which they practiced their profession.

This focus on teaching and teachers in the comparative study of educational systems remained at the core of the field's scholarly pursuits, but contextual factors or phenomena outside the schools also became aspects worthy of closer inspection. Nonetheless, in his oft-quoted address at the Guildford Educational Conference in October 1900, Michael Sadler contemplated the benefits teachers may derive from opportunities to learn about teaching practices and educational systems in other countries by experiencing them first hand:

It would be an excellent thing if considerable numbers of our experienced teachers, both in secondary and in elementary schools, could be sent abroad and to America, in order to see and to judge, and then to tell us when they returned home whether some of the things which they had seen abroad were not an improvement on what is ordinarily done at home. (as cited in Bereday, 1964b, p. 311)

An extensive account of the historical development of CIE is neither necessary nor practical in this space, yet it should be noted that even from the mention of these two notable early scholars in the field, a dichotomous epistemology of research paradigms ensued. Two research traditions seemed to contour and inform the field, namely positivism and relativism (also referred to as contextualism). Without going into much detail here, scholars in the former tradition, sought to apply the scientific method in the comparative study of educational systems, through the formulation of hypotheses regarding discrete and observable variables that lead to generalizable conclusions about the characteristics of educational systems. In turn, scholars in the latter tradition considered that any observation and analysis of educational phenomena needed to be observed as embedded in their particular social, cultural and historical contexts in order to make holistic sense of the functioning of educational systems. Thus, epistemologically, the two traditions could not be further apart and seemed to be eternally irreconcilable as scholars adhering to either tradition disputed the merits of the other in the comparative study of education (Epstein, 2008). In general terms, subsequently, scholars in the positivist realm embraced theoretical lenses informed by structuralfunctionalist approaches such as human capital or modernization theories, along with Marxist orientations exemplified by dependency theory. Conversely, relativists adopted post-modernist or post-structuralist paradigms expressed through critical theories, liberation theory, ecological theories, postcolonialism or feminism (Kubow \& Fossum, 2007). More recently, this repertoire has expanded to globalization theories or post-foundational approaches to comparative education and, certainly, the terrain is more ecclectic today, with scholars employing mixed methodologies and theoretical frameworks. This bodes well for fostering not only comparative, but also interdisciplinary perspectives in the scholarship and practice of teacher education.

In this context, here I set out to provide a succinct examination of two intertwined issues connecting the worlds of CIE and T.Ed.:

- First, I address the place of CIE scholarship in illuminating the functioning, organization, importance and interconnectedness of teaching, as a profession, and teacher education, as the conduit to that profession, across national and cultural settings. In doing so, I will refer explicitly to the extant literature on comparative research in teacher education and provide a concrete illustration of this type of research by showcasing a recent collaborative study I conducted with colleagues in Romania.

- Second, I turn to the place of CIE instructional practice in promoting comparative perspectives in teacher education programs. Here, I focus particularly on the United States, where there has been a gradual erosion of comparative perspective-taking in T.Ed., to the extent that, with a handful of exceptions, comparative education courses or even considerations in professional courses have been eliminated from T.Ed. programs. Once again, I will offer an example of an attempt to reinvigorate the comparative perspective-taking in T.Ed. by highlighting the course and curriculum designs in which I engaged to this end.

In this regard, I combine a review of the current literature in comparative research on teacher education with a reflexive approach to embedding comparative scholarship and practice in teacher education. Thus, the rest of this article is organized as follows: the next section reviews the research literature on CIE in teacher education, with a subsection containing an illustrative example of such research; a section reviewing the state of affairs in the presence of 
comparative instructional practice in teacher education with a subsection providing a curricular design example, and; finally, a brief concluding section summarizing the narrative.

\section{Comparative scholarship in teacher education}

To a certain extent, comparative studies in teacher education have been informed by the epistemological approaches noted earlier. Interest in comparative research in T.Ed. has expanded over the past two to three decades, as the move towards accountability, particularly in North America and parts of Europe has led to intense curiosity on part of researchers, educators and policy-makers related to comparisons of teaching effectiveness, teaching quality, assessment of learning outcomes, professionalization of teaching and teacher education, etc. This interest is evidenced in part by the increasing comparative research literature particularly in international perspective, primarily in scholarly journals, but also in dedicated volumes on explorations of teacher education in cross-national, cross-cultural or international contexts. For example, at the time of this article's writing, a basic search for the term teacher education in the top-three comparative education journals (i.e., Comparative Education Review, Comparative Education and Compare) yielded a combined result of more than 7,000 articles spanning over three decades. Moreover, comparative studies in specialized journals on teacher education also contain a substantial and growing number of articles. Particular focus has been placed on comparative studies in T.Ed. in the Journal of Teacher Education, the European Journal of Teacher Education or the Asia-Pacific Journal of Teacher Education, to name just a few of the most prominent publcations.

Notwithstanding this growing trend, comparative studies in teacher education have been criticized for their rather limited scope, tendency for undertheoretization, attempts to generalize findings from small-scale studies or the cursory attention given to historico-socio-cultural contexts in which teacher education and the teaching practice operate (Afdal, 2019; Tatto \& Menter, 2019). By the same token, the methodological approaches in teacher education research, including in comparative perspective, have been scrutinized and found to tend predominantly toward small-scale, qualitative, rather than large-scale, quantitative approaches (Mayer \& Oancea, 2021). This general orientation towards small-scale studies may be explained through the uniqueness and contextual nature of teacher education programs and the difficulty in extrapolating findings to larger system levels even within one country, particularly in federaltype, decentralized education systems such as the United States, Canada, Australia, Germany, Switzerland or Belgium to name just a few. It may also be explained by what has been termed as the "practical turn" in teacher education (Crossley \& Watson, 2009), which has led to a narrowing focus on the acquisition of discrete skills in teacher education programs. This is particularly the case in North America and the United Kingdom, where the movement toward the professionalization of teacher education and the development of standardized accountability and performance assessment criteria have led to an emphasis on a limited pedagogical content knowledge repertoire at the expense of minimizing or excluding more holistic conceptualizations of teaching expertise. This inevitably marginalizes subjects in the teacher education curriculum deemed as impractical, such as the history of education, sociology of education and, most relevant in this discussion, comparative education.

Consequently, research studies presumably follow this pattern, as structural and organizational aspects of teacher education programs, thus limited by the pragmatic orientations in curriculum design, inform the extent, nature and elements of comparison. Furthermore, a limiting component in comparative teacher education studies rests with the unit of analysis. Over time, comparative education literature has devoted much attention to considerations and definitions of units of analysis in CIE research (Bereday, 1964a; Phillips \& Schweisfurth, 2014). More recently, in their edited volume on approaches and methods in comparative education research, Bray, Adamson and Mason (2016) identified a number of categories of "units of comparison," including places, systems, times, cultures, values, policies, curricula, race, gender and class, etc. This speaks to the varied landscape of CIE research, as well as to the range and levels at which the researcher can focus her or his attention. In comparative teacher education research, the specific and contextual nature of teacher education programs routinely constrains the researchers to narrower units of comparison, given the difficulty in defining easily transferrable elements of comparison across programs or systems. What is defined as teacher effectiveness or teacher quality may present different features and connotations across national or even intra-national contexts, therefore posing difficulty in 
making holistic interpretations at broader systemic levels.

\subsection{An example of cross-country T.Ed. comparison}

Having sketched out some of the fundamental premises and vexing issues of comparative research in teacher education, next I turn to discussing the approach my colleagues in the Department of Educational Sciences at Universitatea Babeș-Bolyai (UBB) in Romania and I took in our collaborative project on comparing teacher education across national contexts in Romania and the United States. To illustrate this, I will briefly review the main aspects of the research study we undertook, comparing the teacher education programs at our respective institutions, namely NDSU and UBB (Salajan, Duffield, Glava \& Glava, 2017). First, conceptually we embedded our study in a framework for creating effective teacher education programs developed by Darling-Hammond et al. (2000). Some of the elements of this framework consisted of, among others, the formulation of a coherent program vision, a conscious bridging of theory and practice, thoughtfully designed field experiences, use of active pedagogy or meeting the needs of diverse learners. Second, the data collection instrument which sought responses from teacher candidates on their experiences in our programs was closely aligned with the components of this framework. Third, we deliberately contextualized the application of this instrument in extensive descriptions of both the histories, educational organization and curricular structures of the two programs and the larger societal settings in which they exist.

Following these steps, while we attempted to identify the strengths and weaknesses of each program, we also carefully sought to avoid to contrast them against each other given the unique settings in which they function. Therefore, contextual interpretations of the findings were paramount, particularly as neither program was actually representative of the entire teacher education system in which it operated. In the final analysis, we were able to draw inferences on the commonalities and differences of teacher education acorss these two contexts, which is what a comparative approach would have yielded, but were also cognizant that these contrasting characteristics can only explain to a limited extent the intricate nature and developmental paths of the two programs. In turn, we acknowledge that the study may be subjected to some of the same criticism I alluded to earlier. For instance, the study was anchored in what may be considered a conceptually sound, but rather practice-oriented than a purely theoretical framework and, therefore, not conducive to generating new theoretizations of teacher education functions in comparative perspective. It was also based on small-scale samples, only partly representative of the socio-cultural contexts informing and surrounding them. However, these limitations do not diminish the methodical and rigorous approach we took in engaging in this comparison, particularly considering the marked differences in the structures, organization, institutional cultures, resource availability and overall societal environments for which the two programs were designed.

This endeavor provided a unique opportunity to juxtapose teacher education programs from two sociocultural settings that had not existed in the published international research literature up to that point. All these are valuable lessons learned, both in terms of comparative aspects of our programs and in further refining our research approach for our future collaborative projects. In fact, it proved to be a stepping stone to further collaboration in comparative projects, as we brought in partners from Israel for a tricountry research study examining the avenues by which first-year teachers in Romania, Israel and the United States experience their transition from the preparation they received in their respective programs to entering the profession. It is immediately evident that adding a third national setting to the research project increases the complexity of the comparison, but it is also bound to provide further nuance that only enriches the findings and mutual learning occurring from the comparative approach.

\section{Comparative approaches in T.Ed. curricula}

The curriculum in preservice teacher education is understandably geared towards ensuring that future teachers are equipped with the requisite subject content knowledge, pedagogical content knowledge and teaching dispositions, so they may successfully perform and accomplish their teaching expectations. Any curriculum designed for these purposes will necessarily weigh the content it includes against the academic and professional standards stipulated by accreditation or certification organizations, whether governmental or non-governmental, the approval of which is expected and paramount for their functioning. 
In the United States, the curricular choices and planning teacher education programs make in this regard are informed by such accreditation bodies as the Council for the Accreditation of Educator Preparation (CAEP), formerly known as the National Council for Accreditation of Teacher Education (NCATE). In this process, preservice teacher education programs are built around a required core of professional education courses, aligned with accreditation standards. Over time, this core has contracted to focus primarily on subjects related to, among others, foundations of teaching, educational psychology, classroom management, instructional planning and methods, assessment and teaching diverse learners. A typical T.Ed. program in the United States leaves very little room for electives outside this professional education core and courses narrowly related to teaching the teacher candidates' chosen content area. The tendency towards a curriculum contraction may be attributed to the turn towards practice-based teacher education in the context of reform cycles promoted by policymakers over time. This brought teacher education under scrutiny as a contested educational policy-making terrain, the result of which was a move to induce a competence-based approach in teacher education in the 1970s (Grossman, 2018). In recent years, efforts to underscore teacher accountability, quality or effectiveness resulted in a gradual infusion of teacher education programs with these concepts as part of the process of professionalization in teacher education (Janssen, Westbroek \& Doyle, 2014; Zeichner, 2012).

In this context, as noted earlier, although it was a core component of teacher education in the 1960s and 70 s, the practical turn resulted in the marginalization and eventual exclusion of comparative and international education as a required subject matter from university-based preservice teacher education curricula in North America, Ireland, the United Kingdom and other parts of Europe (Crossley \& Watson, 2009; O'Sullivan, 2008). The multiple benefits of a comparative perspective taking for preservice teacher education candidates' nuanced understandings about the world of teaching they experience in their own setting in the context of learning about other systems of education or teaching practices has been well-documented (Kubow \& Fossum, 2007; Darling-Hammond \& Lieberman, 2012). Notwithstanding continued calls for a reconsideration of this approach, particularly as preservice teachers are increasingly expected to develop global or intercultural competences as they enter the profession (Aydarova \& Marquardt, 2016), with few exceptions, comparative and international education remains relegated to an elective in most preservice T.Ed. programs. The utilitarian conception that has taken hold of T.Ed. programs (Kubow \& Blosser, 2016) remains an obstacle in infusing their curricula with comparative and international perspectives on teaching, and therefore the inclusion of CIE as a required subject.

Perhaps, the current inertial thinking may reverse its course as more scholars and practitioners advocate for a reevaluation of the exclusion of CIE in teacher education, precisely because in an interconnected world of teaching, an understanding of the global phenomena, policies and practices that undergird teaching and education is fundamental for prospective teachers in inculcating in their students an awareness of their situatedness in the global community. To put it in the utilitarian and pragmatic framework currently governing teacher education, comparative perspective-taking, particularly in international context, should represent core teaching skills for effective student learning and literacy about the codependencies of human action and changes it induces across the globe, as this has direct and indirect impact on the sustainability of all human societies. It is an essential understanding that young learners need to be imparted by teachers trained in comparative meaningmaking of educational systems, teaching practices and learning approaches around the world. For all intents and purposes, if follows that T.Ed. is the natural intellectual and practice-based home for CIE as these programs prepare future teachers to function in a world marked by increasing interdependencies across a multifaceted societal, cultural, economic, political and educational global landscape.

\subsection{An illustration of a comparative approach in} T.Ed. courses

As an evocation of and in adherence to the principles just mentioned, in my own instructional practice in the T.Ed. program at NDSU, I have strived to enrich the teacher candidates' understanding of the world by infusing the courses I teach with brief segments of comparative and international perspectives on education or teaching in other parts of the world. Nonetheless, in the already compact and packed T.Ed. curriculum, there is very little room to dedicate anything but superficial space and time to conceptions of teaching or explorations of educational 
systems around the world. Reserving one class session over the course of a semester to such education outside U.S., does not do justice to the vastly intricate and complex educational structures, phenomena and their inter-relationships in the international arena. My sense was that this had to change and I decided to do something about it.

As is the case with many other T.Ed. programs in the U.S., the T.Ed. program at NDSU is based on a core set of professional education courses that stray very little from the current cannon embracing the "practical turn." Therefore, the curriculum, primarily geared to prepare future high-school teachers, contains courses in the areas enumerated above, namely, foundations of education, educational psychology, instructional planning, to name just a few. Consistent with the literature reviewed here, comparative and international education is not part of the core requirements of the program. Furthermore, at the time I joined the faculty in the department, the program also had no elective course in this area. Certainly, given my academic training as a comparativist, I regarded this absence of CIE in teacher education as a deficiency which had to be remedied. Not long after I started teaching in the department, I had the exciting opportunity to work with a colleague in the doctoral program to co-design and co-teach an introductory doctoral-level course in CIE. We set out to develop the framewok, materials and mode of delivery for this course and had the chance to co-teach it at least three times before my colleague left the program for another professional opportunity.

Nonetheless, this experience further encouraged me to seek ways to provide a similar learning experience to my students in the T.Ed. program. Consequently, six years into my tenure in the program, I designed a course entitled Teacher Education in International Comparative Perspective to be offered as an elective to undergraduate and graduate teacher candidates in our prorgam. Having gone through the longer-than-expected approval process, I finally offered and taught the course for the first time during the Fall 2017 semester to three students, two at the graduate and one at the undergraduate level. Although this sounds like a rather limited and disappointing enrollment, given the relative absence of an institutional culture for internationalization and global engagement, I consider it a small step towards changing that perspective both in our program, department and, possibly, across the university.
Pedagogically and structurally, the course consists of weekly readings focused, in the first stage, on developing an understanding of comparative education and comparative perspective-taking. In subsequent sessions throughout the semester, the course is structured in two-week modules addressing teacher education systems on each continent. In each module, during the first week students conduct a Strengths, Weaknesses, Opportunities and Threats or SWOT analysis of at least three countries' teacher education system or environment which are then discussed in a roundtable format during class (the instructor also prepares a three-country analysis). The following week, a faculty member on campus, either from an international background or with experience in educational systems abroad, an international student or a scholar connecting via distance from a locale in the region under discussion that week is invited into the classroom. This invited guest (or guests, occasionally) presents and engages in a conversation with class members on aspects of teaching/teacher education in the country in which s/he has expertise, with the possibility of extending the discussion at regional level. Certainly, the SWOT analyses the class members conduct the week prior to the conversation with the invited guest serve as background literature and information to enrich the discussion by noting patterns, contrasting various teaching/teacher education settings, and delving deeper into the structural and contextual nature of those settings or systems. At the conclusion of this series of modules, students leave more informed and aware of the complexities, inequalities, challenges, but also possibilities in other teacher education or educational systems, a perspective they would have not acquired without opting for this course.

Certainly, one elective course in CIE offered in the program, which draws a low number of students given the already compressed curriculum, cannot radically change the culture of comparative perspective and engagement with education globally overnight. Although I had the pleasure to teach the course again during the Fall 2019 semester, again with an enrollment of two graduate students and one undergraduate student, I hold out hope that, with subsequent offerings, the course will gain more traction. That is to say that, making it available to students in the program as often as possible may signal to students in the program that this is a valuable component they should explore, until such time that 
the practical turn may wane and CIE becomes mainstreamed again into T.Ed. curricula.

\section{Concluding reflections}

I have attempted here to offer an overview of the place of CIE both as a research and teaching component in T.Ed. It is evident from this rather brief reflexive exploration that $\mathrm{CIE}$ is an indelible, critical and integral component of teacher education in both regards and I consider this holds true across national contexts. It is as much valid in the United States as it is in Romania or any other country's educational system. Whether it entails promoting continued scholarly engagements in comparative projects in teacher education across national settings or redoubling efforts in advocating for the inclusion of comparative prespectives in the T.Ed. curricula, it is clear that comparativist researchers and educators have a central role to play in engendering change in this regard.

In sharing my humble experiences in engaging in both the scholarship and instructional practice of CIE in teacher education, I attempted to illustrate just some modalities in which we, as scholars, can promote the inclusion of comparative perspective-taking and its advantages to developing in our teachers-to-be a comprehensive, pragmatic, yet sophisticated and thoroughly informed understanding of education at home and abroad. It is in our, their and their future students' interests that CIE and T.Ed. become and remain closely intertwined.

\section{Acknowledgments}

This article is based in part on the keynote address I delivered at the $9^{\text {th }}$ International Conference Education, Reflection, Development, held online by the Department of Educational Sciences at Universitatea Babeș-Bolyai, Cluj-Napoca, Romania on June 25, 2021. I would like to extend my gratitude to my colleagues, Prof. univ. dr. Ion Albulescu, Conf. univ. dr. Adina Glava and Conf. univ. dr. Catalin Glava for their generous invitation to give this presentation.

\section{Authors note:}

Florin D. Salajan is Professor in the School of Education at North Dakota State University, Fargo, USA. He teaches undergraduate and graduate courses in comparative education, teacher education, educational research and instructional methods. His areas of research interests include Comparative and International Education, European higher education policies, European educational policy analysis, teacher education in comparative perspective, comparative elearning, and information and communication technology in teaching and learning. Among the scholarly journals in which his research has been published are the Comparative Education Review, Compare, European Journal of Education, European Educational Research Journal, European Journal of Higher Education, and Educational Policy. More recently, he co-edited and contributed chapters for the volume titled, The Educational Intelligent Economy: Big Data, Artificial Intelligence, Machine Learning and the Internet of Things in Education as part of the International Perspectives on Education and Society volume series (with Tavis D. Jules, Emerald 2019).

\section{References}

Afdal, H. W. (2019). The promises and limitations of international comparative research on teacher education. European Journal of Teacher Education, 42(2), 258275. https://doi.org/10.1080/02619768.2019.1566316

Aydarova, E., \& Marquardt, S. K. (2016). The global imperative for teacher education: Opportunities for comparative and international education. FIRE: Forum for International Research in Education, 3(1), 23-41. http://preserve.lehigh.edu/fire/vol3/iss1/3

Bereday, G. Z. F. (1964a). Comparative method in education. Holt, Reinhart and Winston, Inc.

Bereday, G. Z. F. (1964b). Sir Michael Sadler's "Study of Foreign Systems of Education." Comparative Education Review, 7(3), 307-314. https://www.jstor.org/stable/1187111

Bray, M., Adamson, B., \& Mason, M. (2016). Comparative education research, Second edition. Springer.

Crossley, M., \& Watson, K. (2009). Comparative and international education: policy transfer, context sensitivity and professional development. Oxford Review of Education, 35(5), 633-649. http://dx.doi.org/10.1080/03054980903216341

Darling-Hammond, L., Macdonald, M. B., Snyder, J., Whitford, B. L., Ruscoe, G., \& Fickel, L. (2000). Studies of excellence in teacher education: Preparation at the graduate level. Washington, DC: AACTE Publications. http://eric.ed.gov/?id=ED468433

Darling-Hammond, L., \& Lieberman, A. (2012). Teacher education around the world: Changing policies and practices. Routledge.

Epstein, E. H. (2008). Setting the normative boundaries: Crucial epistemological benchmarks in comparative 
education. Comparative Education, 44(4), 373-386. https://www.jstor.org/stable/29727903

Epstein, E. H. (2017). Is Marc-Antoine Jullien de Paris the 'father' of comparative education? Compare: A Journal of Comparative and International Education, 47(3), 317331. https://dx.doi.org/10.1080/03057925.2016.1254542

Grossman, P. L., Schneider Kavanagh, S., \& Pupik Dean, C. G. (2018). The turn towards practice in teacher education: An introduction to the work of the core practice consortium. In P. L. Grossman (Ed.), Teaching core practices in teacher education. Harvard University Press.

Hayhoe, R., Manion, C., \& Mundy, K. (2017). Why study comparative education? In K. Bickmore, R. Hayhoe, C. Manion, K. Mundy, \& R. Read (Eds)., Comparative and international education: Issues for teachers, Second Edition (pp. 1-26). Canadian Scholars' Press Inc.

Janssen, F., Westbroek, H., \& Doyle, W. (2014). The practical turn in teacher education: Designing a preparation sequence for core practice frames. Journal of Teacher Education, 65(3), 195-206. https://doi.org/10.1177/0022487113518584

Kubow, P. K., \& Fossum, P. R. (2007). Comparative education: Exploring issues in international context, Second Edition. Pearson.

Kubow, P. K., \& Blosser, A. H. (2016). Multicultural education is not enough: The case for comparative education in preservice teacher education. In
P.K. Kubow \& A.H. Blosser (Eds.), Teaching comparative education: Trends and issues informing practice (pp. 75-90). Symposium Books.

Mayer, D., \& Oancea, A. (2021). Teacher education research, policy and practice: Finding future research directions. Oxford Review of Education, 47(1), 1-7. https://doi.org/10.1080/03054985.2021.1853934

O'Sullivan, M. (2008). Comparative and international education in initial teacher education: an Irish case study. Irish Educational Studies, 27(3), 241-251. https://doi.org/10.1080/03323310802242179

Phillips, D., \& Schweisfurth, M. (2014). Comparative and international education: An introduction to theory, method, and practice, Second edition. Bloomsbury Academic.

Salajan, F. D., Duffield, S. K., Glava, A. E., \& Glava, C. C. (2017). A comparative study of two pre-service teacher preparation programmes in the USA and Romania. Compare, $\quad 47(4)$, https://doi.org/10.1080/03057925.2016.1246955

Tatto, M. T., \& Menter, I. (2019). Knowledge, policy and practice in teacher education: A cross-national study. Bloomsbury.

Zeichner, K. (2012). The turn once again toward practicebased teacher education. Journal of Teacher Education, 63(5), 376-382. 